\title{
Erratum to: When is a Firm Born? Alternative Criteria and Consequences
}

\author{
PAUL DAVIDSON REYNOLDS
}

\author{
Correction to: Business Economics (2017), \\ DOI 10.1057/s11369-017-0022-8, \\ published online 22 February 2017
}

W e regret that Figures 4, 5 and 6 were incorrectly labelled in the original version of this article. The horizontal axis of Figure 4 was not labelled, but it should have read "Months since entry into startup process". The horizontal axis label for Figure 5 was incorrectly labelled as "Months since entry into start-up process". It should have read "Months since firm birth". Lastly, Figure 6 displayed an erroneous horizontal axis label of "Months since firm birth". The axis should have been unlabelled. Corrected figures are shown below and no other element of the article is under question. 
Figure 4. Percentage of ventures reporting employment after start-up

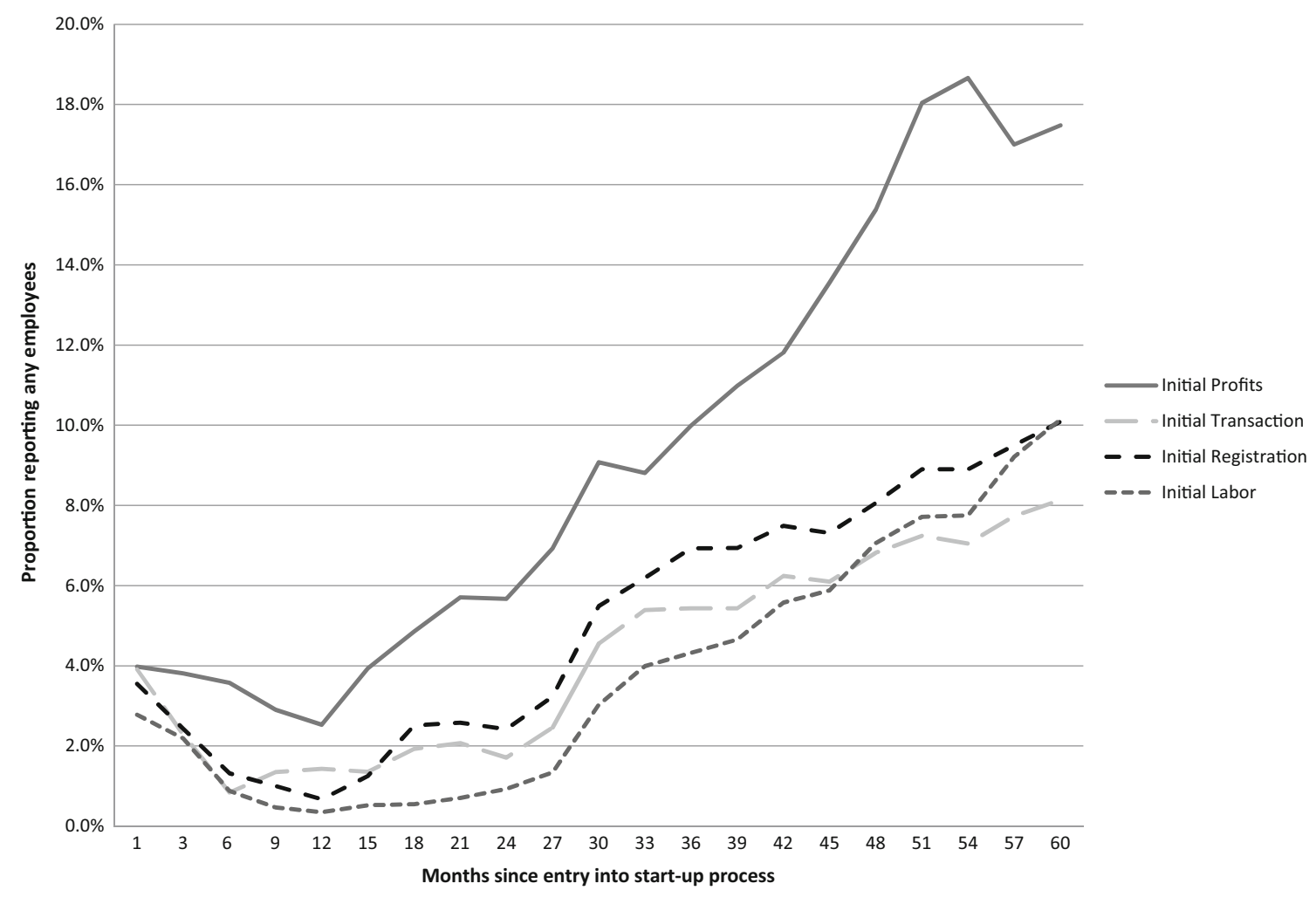

Figure 5. Percent of new firms reporting employment after birth

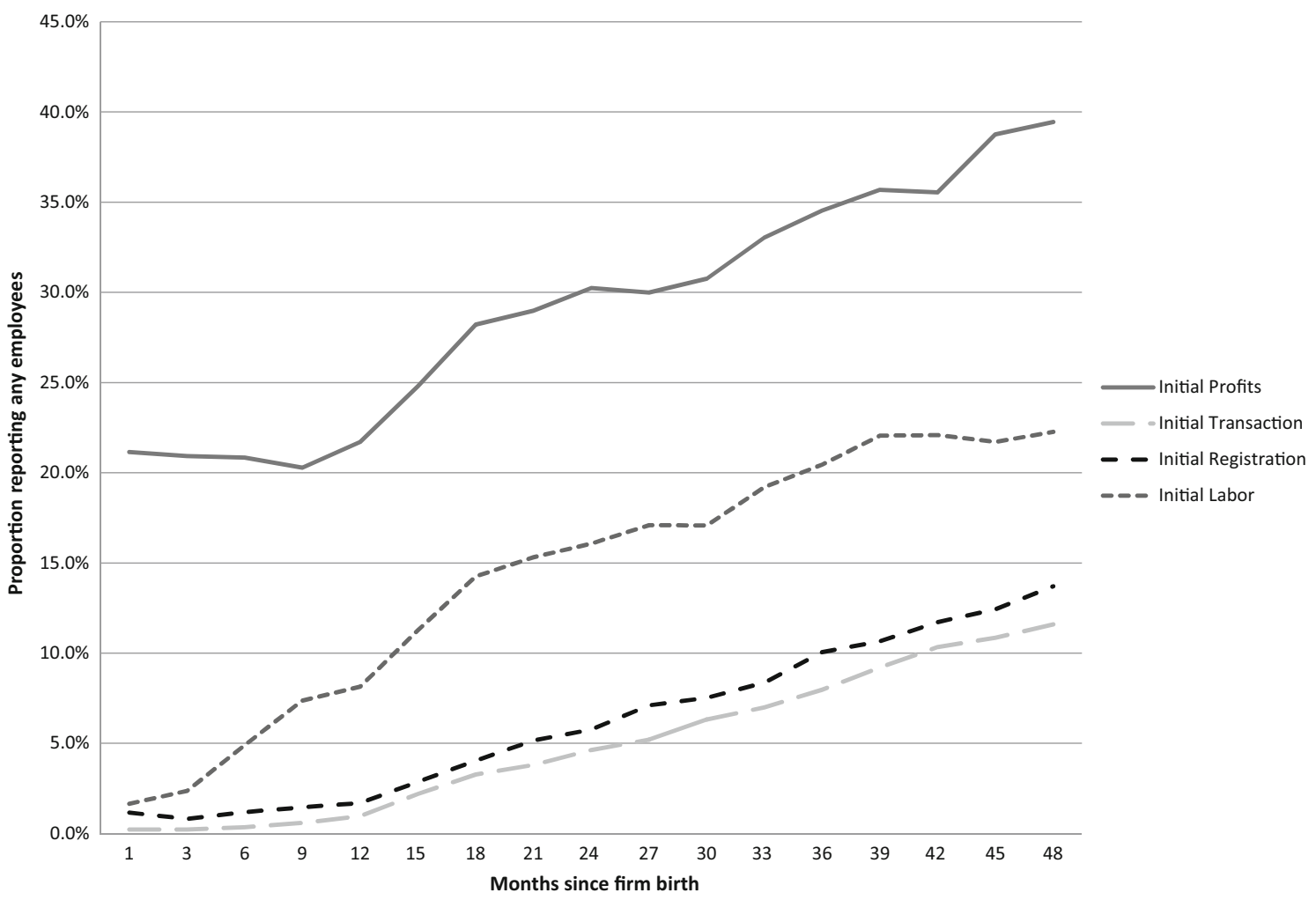


Figure 6. Lag from entry into start-up process to reporting of activity

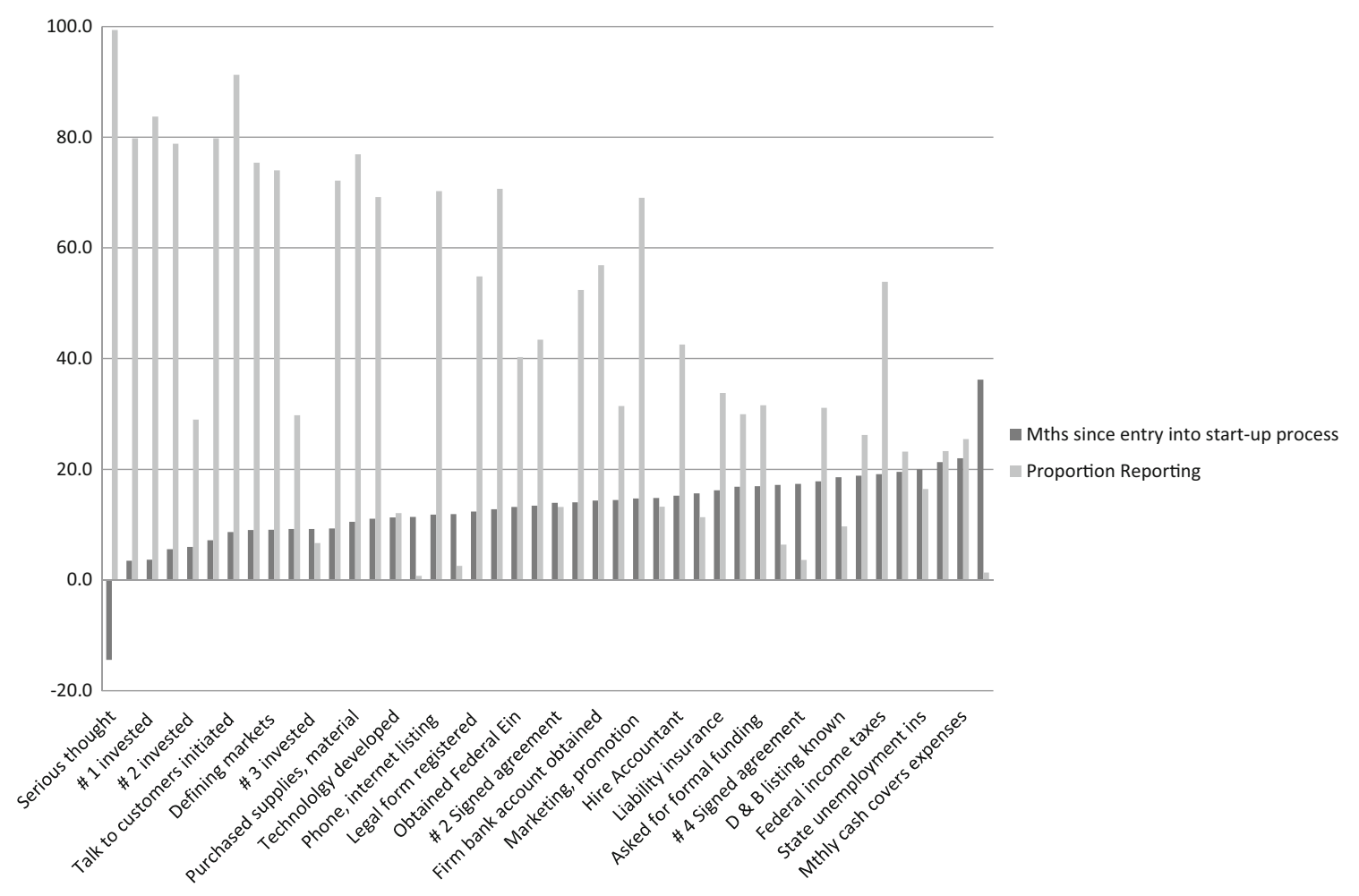

